\title{
Assessment of the callus induction, relative growth rate, proline and sugar in Saussrea lappa C.B. Clarke
}

\author{
Zaib-Un-Nisa ${ }^{1 *}$, Samin Jan ${ }^{1}$, Safdar Hussain Shah ${ }^{2}$, Ghulam Farooq ${ }^{3}$, \\ Muhammad Anwar Sajad ${ }^{1}$ and Muhammad Anwar Saleem Khan ${ }^{4}$ \\ 1. Department of Botany, Islamia College (A Public Sector University) Peshawar, Peshawar-Pakistan \\ 2. Institute of Biotechnology and Genetic Engineering, Agriculture University-Peshawar-Pakistan \\ 3. Department of Genetics, Hazara University, Mansehra-Pakistan \\ 4. Department of Zoology, University of Swabi, Khyber Pakhtunkhwa Pakistan \\ *Corresponding author's email: zaib2864@ gmail.com \\ Citation \\ Zaib-Un-Nisa, Samin Jan, Safdar Hussain Shah, Ghulam Farooq, Muhammad Anwar Sajad and Muhammad Anwar \\ Saleem Khan. Assessment of the callus induction, relative growth rate, proline and sugar in Saussrea lappa C.B. \\ Clarke. Pure and Applied Biology. Vol. 8, Issue 1, pp838-846. http://dx.doi.org/10.19045/bspab.2019.80025

\begin{tabular}{llll}
\hline \hline Received: 06/12/2018 & Revised: 25/02/2019 & Accepted: 04/03/2019 & Online First: 11/03/2019 \\
\hline \hline
\end{tabular}

Abstract

Saussurea lappa is a critically endangered medicinal plant. It is necessary to conserve it. Plant tissue culture is one of the best way for its conservation. For callus induction apical shoots of S. lappa was sterilized with $0.1 \%$ mercuric chloride for 2 minutes and cultured on MS media supplemented with $1 \mathrm{mgl}^{-1}$ Dichlorophenoxy acetic acid (2-4 D) and $0.25 \mathrm{mgl}^{-1}$ kinetin $(\mathrm{Kn})$. The callus induction occurred after 3-7 days of inoculation. The Relative Growth Rate Week ${ }^{-1}$ (RGR) of the callus was calculated on fresh weight basis. Calculation revealed that a little decrease in RGR was found with increase in time duration. Statistically non-significant differences were found in RGR of the calli calculated week wise for three weeks. The best grown 2 weeks old calli, shoot callus (a) and root callus (b) were used to quantify proline and sugar concentration and compared to cultivated plant parts (root, petiole and lamina). Callus (b) was significantly higher in proline content $\left(162.337 \mu \mathrm{Mg}^{-1}\right)$ and the soluble sugar content was significantly higher $\left(234.182 \mu \mathrm{Mg}^{-1}\right)$ in callus (a) compared to all other samples, whereas in plant parts root was found more efficient in proline $\left(53.187 \mu \mathrm{Mg}^{-1}\right)$ and sugar $\left(200.084 \mu \mathrm{Mg}^{-1}\right)$ content compared to petiole and lamina. All samples showed statistically significant difference on both total soluble sugar and proline content. Results showed that S. lappa callus induction rate was high in one and two weeks old calli which indicated that callus should be subculture after two weeks. Callus was found to contain maximum concentration of both proline and sugar compared to root, petiole and lamina of the field grown plant. Whereas among plant parts root was found to contain high proline and sugar content compared to petiole and lamina.

Keywords: Callus Induction; Proline and Sugars Content; Relative Growth Rate; Saussurea lappa

Introduction

It is a common and significant observation that plants unable to run away or use vigorous arms when attacked by animals like herbivore, vertebrate, mollusk, insect or worm. Human, animals and microbes can protect themselves through their welldeveloped natural and acquired immune system, but in plants such an immune system is missing. Though, plants have been about for more than 400 million years on earth and successfully survived although being 
challenged by animals and microorganisms $[1,2]$. To overcome these problems, plants produced two types of metabolites; primary and secondary metabolites. Protein, carbohydrates, lipids and amino acids are called primary metabolites. These primary metabolites are very essential for growth and metabolism of plant. Therefore, they are synthesized in large quantity [3].

S. lappa C.B. Clarke, belongs to Family Asteraceae (Compositae) and commonly known as costus [4]. It is used against a lot of diseases like head ache, pain, arthritis, skin diseases, ulcers, cough, flatulence, asthma, colic, fever, general weakness [5] and diarrhea etc [6]. The over exploitation of $S$. lappa for diverse commercial and medicinal purposes gradually decreases the availability of this plant in wild. Tissue culture is the only solution for its conservation. The primary aim of the current study is to properly sterilize the explants and determine the relative growth rate of S. lappa callus at three weeks duration. Compared the two types (shoot callus and root callus) calli with cultivated plant parts for their primary metabolites (proline and sugar contents) and also determined the efficient plant part for them.

\section{Materials and methods \\ Explants source and preparation of plant materials}

The seeds and cultivated plant of S. lappa were collected from the Pakistan Herbal Garden of Forest Institute, Agricultural University, Peshawar, Khyber Pakhtunkhwa (KP) Pakistan. The seeds were first washed with tape water followed by $5 \%$ solution of Tween-20 for 30 minutes. Then washed five times with distilled water followed by sterilization with $0.2 \%$ aqueous solution of mercuric chloride for 8 minutes. After treatment with $0.2 \%$ mercuric chloride the explants were again washed five times with sterilized distilled water. The seeds were placed in autoclaved petri dish containing filter paper and small amount of water. The whole procedure was performed inside the laminar flow [7].

\section{Preparation of explants and culturing}

Four days old seedlings were taken and sterilized again with $0.1 \%$ mercuric chloride for 2 minutes and rinsed five times with sterilized distilled water. The sterilized explants were placed on MS media in flasks. The procedure of dissecting explants was done in the laminar flow under aseptic conditions. Before dissecting the explants, all the instruments were autoclaved for 20 minutes; hands were washed with $75 \%$ ethanol. For aseptic manipulation the dissecting instruments such as sterilizing bottles, scalpel, blades and forceps were sterilized. In order to diminish the possibility of infection, all the instruments were dipped in antiseptic (ethanol) and must flame after every one operation [7].

\section{Inoculation}

The de husked seeds, seedling, shoot and root explants were picked up with the help of sterilized forceps and inoculated in $100 \mathrm{ml}$ flasks containing MS medium fortified with 2-4 D + Kn $\left(1 \mathrm{mgL}^{-1}+0.25 \mathrm{mgL}^{-1}\right)$ and 2-4 D $\left(1 \mathrm{mgL}^{-1}\right)$ alone and also a medium without growth regulators used for callus induction. Single explant was inoculated per flask. In order to get maximum sterilization, forceps were kept in ethanol and then burned with flame after every inoculation. The whole process of inoculation was carried out in a closed proximity to the flame to diminish the chance of contamination. The cultured flasks were sealed tightly with aluminum foil and para film and labeled after inoculation. Then the $100 \mathrm{ml}$ flasks were placed in growth room, where the cultured flasks were kept under dark conditions. The flasks were monitored for contamination. Callus initiation of S. lappa seeds were observed daily. The effect of sterilization was observed as percentage of contamination free flasks containing medium and the days of 
callus induction were noted [8]. Two weeks old callus was used for relative growth rate shoot (callus a) and root (callus b) of micropropagated plant were used for callus induction to determine proline and soluble sugar content.

\section{Relative growth rate per week}

For the determination of the callus Relative Growth Rate the process of Shah et al. [7] was used. Initial fresh weight and final fresh weight of the callus was recorded. The callus growth was expressed as relative growth rate (RGR) week ${ }^{-1}$ using equation (A) as given below:

RGR = In (final weight of callus) - In (initial weight) / 2 week $^{-1}$

Callus was harvested after several subsequent sub cultures. For further proline and sugar analysis callus of 2 weeks old was selected.

\section{Organic solutes extraction}

The procedure of [9] was used to extract the organic solutes; $0.2 \mathrm{~g}$ fresh tissues frozen in liquid nitrogen were homogenized at room temperature in $4 \mathrm{ml}$ methanol: chloroform: water (MCW) (12:5:1/V) and for five minutes centrifuged at $3 \times 1000 \mathrm{rpm}$. The supernatants were removed and re-extracted the pellets in the same volume of extraction buffer (MCW). For the separation of upper methanol water layer and lower chloroform layer, $3 \mathrm{ml}$ water and $2 \mathrm{ml}$ chloroform was added to every $8 \mathrm{ml}$ of extract. With the help of Para film the extract was Stoppard tightly, stored in dark at $4^{0} \mathrm{C}$, and was used for the purpose to determine total soluble sugars and proline. The method of Singh et al. [9] was used for proline determination. Acid Ninhydrin, 6 molar phosphoric acid, Glacial acetic acid and Toluene were used as reagents. To prepare Acid ninhydrin, $3.75 \mathrm{~g}$ ninhydrin was warmed in $60 \mathrm{ml}$ of 6 molar phosphoric acid and $90 \mathrm{ml}$ glacial acetic acid, agitated until dissolved while 6 molar phosphoric acid was prepared by making the volume of $395 \mathrm{ml}$ phosphoric acid up to 1000 $\mathrm{ml}$.

From the upper water and methanol fraction layer of each one extract, $0.2 \mathrm{ml}$ of sample were taken in test tubes and added $0.8 \mathrm{ml}$ of water, $1.5 \mathrm{ml}$ acid ninhydrin as well as $1.5 \mathrm{ml}$ glacial acetic acid. For about 45 minutes these samples were heated in a boiling water bath and then were cool in cold water. At last $5 \mathrm{ml}$ toluene was added. For two layers separation, test tubes containing samples were shake at vortex mixer and then left for about 30 minutes. Four standards $(0,0.2,0.5$, $1 \mu \mathrm{M})$ of L-proline were prepared and at 515 $\mathrm{nm}$ absorbance was measured against a toluene blank on UV visible spectrophotometer (UV-700).

\section{Total sugars estimation}

Total soluble sugars were measured by Dubois et al., [10] method. Methanol/water (by volume 67:43), 5\% phenol, concentrated sulphuric acid and D-Glucose were used as reagents.

From the extraction upper layer $0.2 \mathrm{ml}$ of sample was taken in test tube and was added $1.8 \mathrm{ml}$ of distilled water. Then added $1 \mathrm{ml}$ of $5 \%$ phenol and at last $5 \mathrm{ml}$ of concentrated sulfuric acid was added but with a rapid delivery pipette that was given dark color. The test tubes were shaked for 10 minutes and placed at $25^{\circ} \mathrm{C}$ to $30^{\circ} \mathrm{C}$ in a water bath. Standards of D-Glucose $(0,2,5 \mu \mathrm{M})$ was prepared and measured the absorbance at 490nm against D-glucose blank on UV visible spectrophotometer (UV-700).

\section{Statistical analysis}

The whole experimental data was one factorial set up conducted with completely randomized design (CRD) with three replications per treatment.

\section{Results \\ Relative growth rate of calli at three different times}

The calli data of RGR week ${ }^{-1}$ is illustrated in the (Figure 1). The RGR week ${ }^{-1}$ of seedling calli was calculated on the basis of callus 
fresh weight. The (Figure 1) indicates the results of three weeks. Callus showed maximum growth after one week $(0.158$ week $^{-1}$ ) followed by two weeks old callus (0.141 RGR week ${ }^{-1}$ ) while three weeks old callus showed less (0.115) RGR week ${ }^{-1}$. With increase of time duration a little decrease was found in RGR. ANOVA showed overall non-significant difference between the calli RGR week ${ }^{-1}$ (Figure $3 \& 4$ ). Relative growth rate of calli from different explants

The relative growth rates of different explants were determined after 15 days of subculture. It was observed that the totipotency rate was high in young explants. The highest 0.141 RGR $^{\text {week }}{ }^{-1}$ was found in seedling callus while the lowest 0.016 RGR week $^{-1}$ was observed in lamina derived callus. However, non-significant results were occurred between root $(0.098$ RGR week $\left.^{-1}\right)$ and petiole (0.082 RGR week $\left.{ }^{-1}\right)$ derived callus. The (Figure 2) shows the relative growth rate of four different explants.

Proline content in in vitro calli and plant samples

The data regarding proline contents in shoot derived callus (callus a), root derived callus (callus b), cultivated plant root (root a) collected from Forest Institute Peshawar is illustrated in (Figure 3). Results showed that root callus (callus b) had significantly higher $\left(162.33 \mu \mathrm{Mg}^{-1}\right)$ proline contents compared to $\operatorname{root}\left(143.833 \mu \mathrm{Mg}^{-1}\right)$, shoot callus (callus a) $\left(53.187 \mu \mathrm{Mg}^{-1}\right)$, petiole $\left(25.899 \mu \mathrm{Mg}^{-1}\right)$ and lamina $\left(19.368 \mu \mathrm{Mg}^{-1}\right)$. Further the highest level of proline accumulation was observed in roots of S. lappa plant compared to petiole and lamina. ANOVA showed higher significant differences in proline content of tested samples.

Total soluble sugar content:

Data presenting total soluble sugar content is presented in (Figure 4). Petiole and lamina showed significant differences from other tested samples. The content of soluble sugar was higher $\left(234.182 \mu \mathrm{Mg}^{-1}\right)$ in callus (b) compared to all other samples. Callus (a) $\left(207.258 \mu \mathrm{Mg}^{-1}\right)$ and $\operatorname{root}\left(200.084 \mu \mathrm{Mg}^{-1}\right)$ showed less difference from each other. However, root showed higher concentration than lamina and petiole. Petiole showed minimum concentration of soluble sugar (30.088 $\mu \mathrm{Mg}^{-1}$ ) compared to callus (b), callus (a) and roots but greater than lamina $\left(12.593 \mu \mathrm{Mg}^{-1}\right)$ which showed much less concentration. ANOVA showed statistically significant difference on total soluble sugar accumulation.

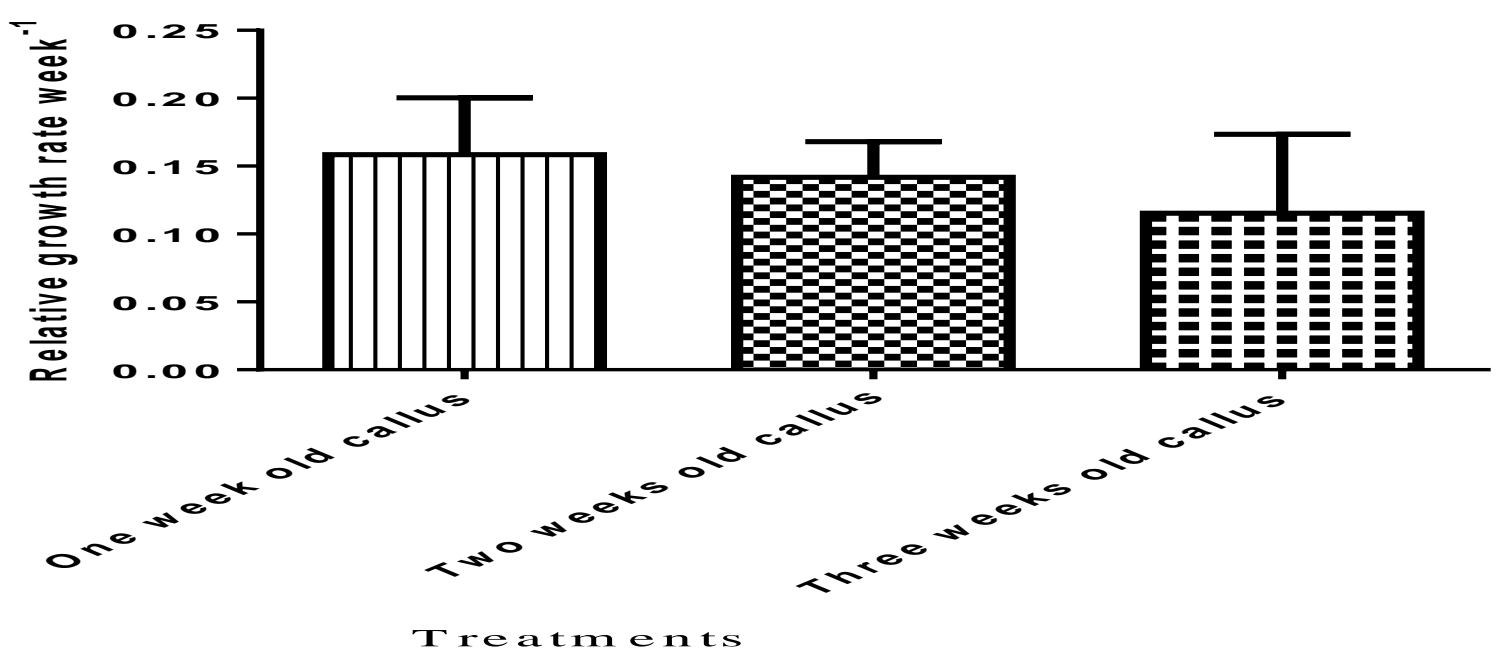

Figure 1. The effect of days on calli relative growth rate. The data in graph are the means of three replicates \pm SD. 


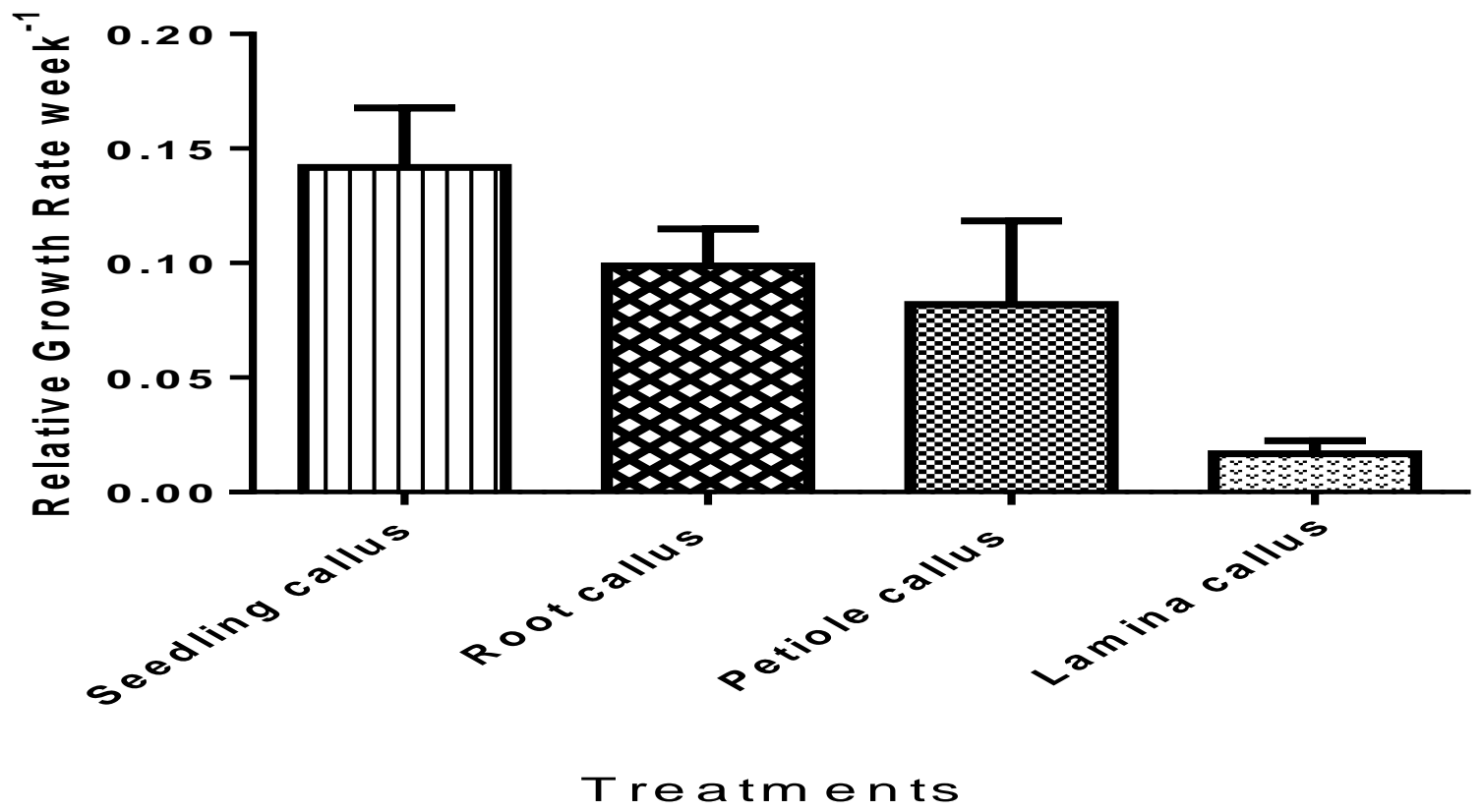

Figure 2. Relative growth rate of different explants. Differences between graphs are the means of three replicates \pm SD.

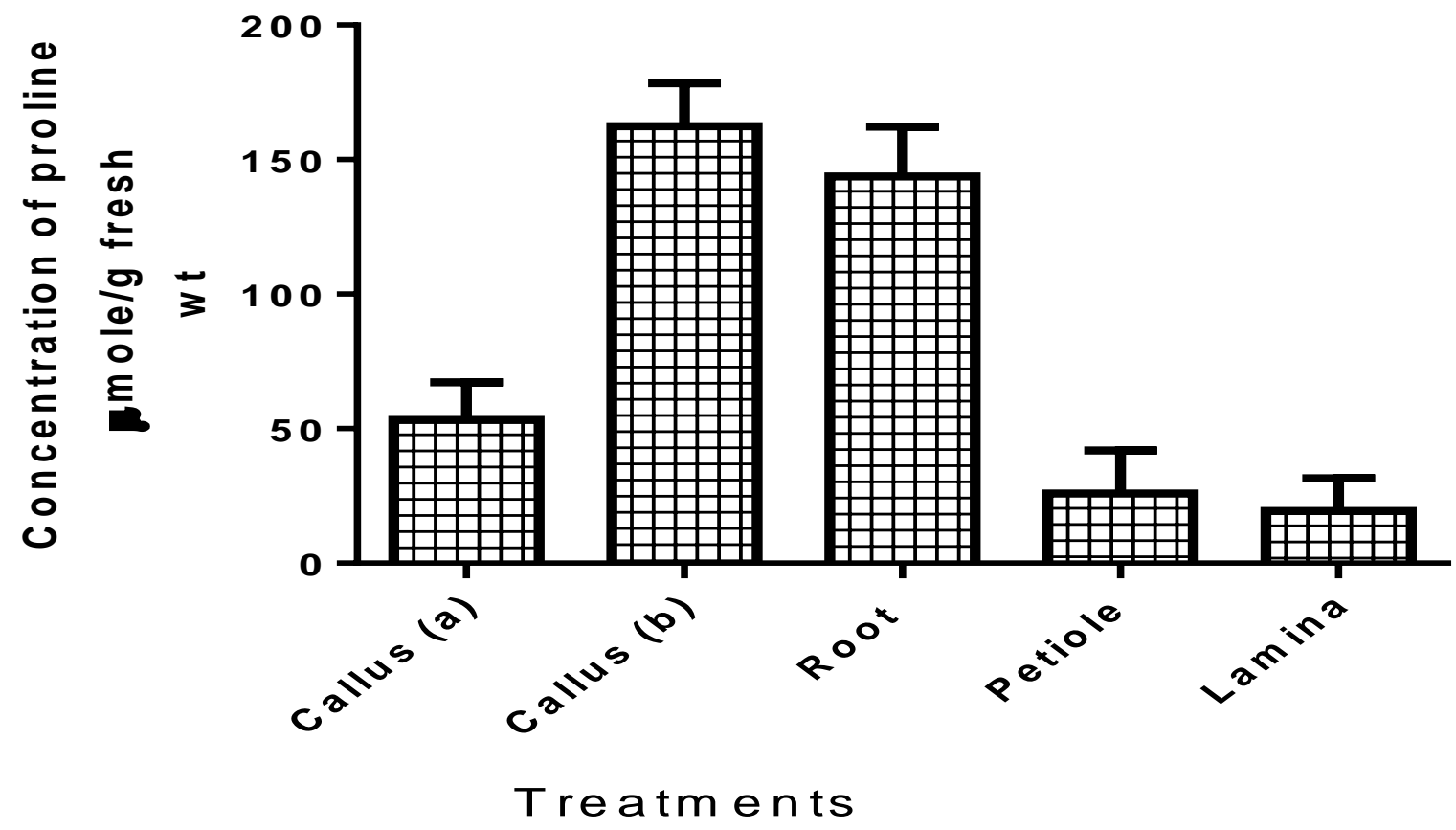

Figure 3. Concentration of proline in different samples. Data presented in graph are the means of three replication \pm SD. 


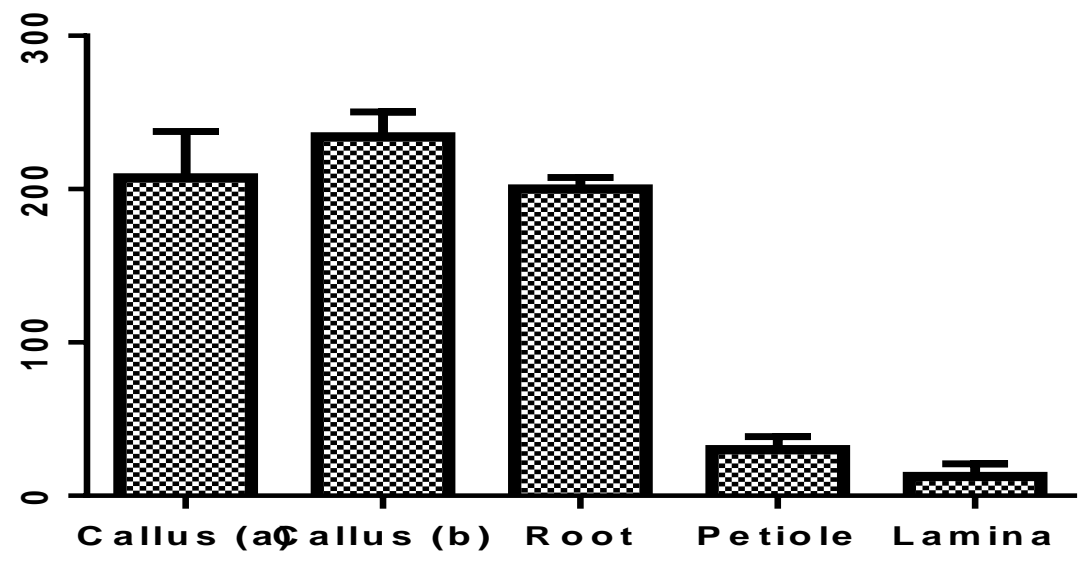

Treatments

Figure 4. Concentration of total soluble sugar in test samples. Differences between graphs are the means of three replicates $\pm \mathrm{SD}$.

\section{Discussion}

Callus relative growth rate

The highest callus content was found in seven days and 14 days old cultured callus (Figure 1) and also calli were healthy and white in color. After two weeks the RGR reduced and calli turn brown in color. Thus, calli were maintained at two weeks intervals with subcultures onto a new medium to generate stable callus cultures and to sustain callus viability. From the results it is cleared that increase of time duration bring a little decrease in RGR because the age of the callus play very important role in regeneration. Generally calli with less age have more totipotency as compared to old calli. Callus culture on MS medium without any stress was found to be healthier for two weeks (14 days). The calli were looked light yellow to whitish in color. But after two weeks the calli were turned brown. The browning rate was observed good indicator of callus sensitivity and showed that increasing time duration is lethal for calli of $S$. lappa. Thus it was better to subculture callus on fresh medium after every 14 days of culture. Similar reports in some previous work have been reported [11-13]. In two weeks old callus the cells vacuole increased in size and accumulate maximum water. These results are supported by Al-Taha, [14] that calli cultured on MS medium gave the highest water content and fresh weight (RGR). The calli relative growth rate was decreased with increase of culture duration as due to deficiency in water content in media some cells become die. These results were also described by Nawaz et al. [11]. However, Ahmad et al. [15] reported that content of sodium ions affects the dry weight of calli as maximum content of sodium ions in callus culture increased dry weight of callus in rice.

\section{Different explants and callus induction}

Regarding the morphogenic potential of different explants (seedling, seed and lamina, petiole and root from micropropagated plant) of $S$. lappa used for induction of callus which started at the cut edges and covered the entire surface of explants after several subsequent subcultures. All the explants were responded different significantly from each other 
(Figure 2), when cultured on same MS media supplemented with similar growth regulators combinations. As growth regulators in vitro induces callus formation by stimulating cell division, cell growth and DNA replication. The signaling networks of hormones influence the parameters of cell cycle and establish functional links between the cell cycle regulatory mechanisms and genes involved in formation of callus. The seedling about three days old was used because it was generated from sterilized seeds placed in petri dishes in sterilized distilled water only. There was no growth regulator or nutrients so the chances of tissue death was high, thus used after 3 days. Roots, lamina and petiole taken from micropropagated plant were found efficient for callus initiation and production because the totipotency is high in young plant parts. It may be due to minimum combination of growth regulators of explants whereas, the growth regulators combination in petiole, root and seedling explants were high. The leaf explants taken from field grown plant took 56 days to initiate callus. Our results coincide with the previous findings [16-18] Similar findings were reported by Abdel-Rahim et al., [19] and Huang et al., [20], that roots and petiole are efficient in callus initiation while lamina took more days and also produce less amount of calli.

Calli produced was very soft, compact, globular and light green in case of petiole and root explants while found friable, white from lamina explants at the beginning of the culture period and after several subcultures all calli turned whitish in color. After 18-20 days it turned dark gray. Calli darkening was almost certainly due to some the phenolic compounds production and oxidation, released by the explants. Thus, calli were maintained at two weeks intervals with subcultures in a new medium to generate stable callus cultures and to sustain callus viability of $S$. lappa, otherwise the calli became dark and growth ceased. These results concide with some other reports [2123].

\section{Proline and soluble sugar content}

Proline and soluble sugar contents were determined because these are the primary metabolites of the plant and provide energy for the production of secondary metabolites. Further, high content of total soluble sugars is essential for the production of energy, cellular membrane stabilization, turgor maintenance, and verification of the cytoplasm and signaling which possibly give plants/cells tolerance against heavy metal stress. Total soluble sugar and proline appear to protect hyacinth bean from osmotic and ionic stress induced by $\mathrm{Zn}$ stress [24]. The content of proline was higher significantly in root calli (callus b) followed by cultivated plant root while shoot calli (callus a), petiole and lamina showed lower proline contents (Figure 3). As the temperature of growth chamber was less than the external environment and according to Putnik-Delic et al. [25] proline content is high in plants of cold regions. This comparative lower temperature of growth chamber than external environment may cause increase in proline contents of root calli. Similarly lower contents in petiole and lamina justified the statement because these plants were collected from regions with comparatively higher temperature. On the other hand lower proline contents in shoot calli did not justify the statement. The highest level of proline and sugar was observed in callus (b) and root of S. lappa plant compared to petiole and lamina. Such accumulation of proline and soluble sugar has been reported in some other medicinal plants as well $[3,25,26]$. However, the content of soluble sugar was significantly higher in callus (a) compared root, petiole and lamina. Callus (b) and root showed less difference in sugar concentration from each other but it was higher than lamina and petiole (Figure 4) 
because tap roots contained more or additional sugars than leaf and stem of plant. Similar findings were reported by Marler and Lindstrom [27].

\section{Conclusions}

S. lappa is an important and endangered medicinal plant. Serious efforts are needed to conserve it by rapid in vitro technique. It is concluded from our work that callus of $S$. lappa needs to be subculture on to fresh culture medium after 14 days. The primary metabolites are observed higher in concentration in plant root and also in root derived calli.

\section{Authors' contributions}

Conceived and designed the experiments: ZU Nisa, Performed the experiments: ZU Nisa, Analyzed the data: G Farooq, Contributed materials/ analysis/ tools: SH Shah, S Jan, Wrote the paper: MA Sajad \& MAS Khan.

\section{Acknowledgement}

The authors would like to express their appreciation to the chairman, Institute of Biotechnology and Genetic Engineering and department of Chemistry, Agriculture University, Peshawar, Pakistan.

\section{References}

1. Schmeller T, El-Shazly A \& Wink M (1997). Allelochemical activities of pyrrolizidine alkaloids: Interactions with neuroreceptors and acetylcholine related enzymes. J Chem Ecol 23: 399416.

2. Wink M \& Schimmer O (2010). Molecular modes of action of defensive secondary metabolites. In functions and Biotechnology of plant secondary metabolites. Annual Plant Reviews 39; Wink, M., Ed.; London, UK, pp 21-161.

3. Yaish MW (2015). Proline accumulation is a general response to abiotic stress in the date palm tree (Phoenix dactylifera L.). Gene Mo Res 14(3): 9943-9950.
4. Kirtikar KR \& Basu BD (2001). Indian Medicinal Plants, vol. 6 second ed. Oriental Enterprises. pp 1961-1965.

5. Gupta OP, \& Ray GBJ (1967). Pharmacological investigations on Saussurea lappa (Clarke). Indian J Med Res 55:10.

6. Arora $\mathrm{R}, \&$ Bhojwani SS (1989). In vitro propagation and low temperature storage Sassurea lappa CB. Clarke - an endangered medicinal plant. Plant Cell Rep 8: 44-47.

7. Shah SH, Ali S, Jan SA, Din J \& Ali GM (2015). Callus induction, in vitro shoot regeneration and hairy root formation by the assessment of various plant growth regulators in tomato (Solanum lycopersicum Mill.) J Anim Plant Sci 25(2): 528-538.

8. Ahmad M, Nangyal H, Imran M \& Ullah F (2016). Optimization of Protocol for Surface Sterilization and Callus Induction for Three Rice Varieties AmEuras. J Agri Env Sci 16: 357-361.

9. Sing TN, Paleg LG \& Aspinall D (1973). Stress metabolism. I. Nitrogen metabolism and Growth in barly plant during water stress. Inter J Biol Sci 6: 47-56.

10. Dubois M, Gillies KA, Hamilton TK, Rebers PA \& Smith F (1956). Colorimetric method for determination of sugars and related substances. Anal Chem 28(3): 350-35.

11. Nawaz S, Ahmed N, Iqbal A \& Khaliq I (2013). Optimization of regeneration protocols for wheat under drought and salt stress. Pak J Agri Sci 50(4): 663 670.

12. Rashid H, Hameed S, Chaudhry Z, Thair F \& Qurashi A (1994). Quantitative protein from embryogenic and nonembryogenic calli. Agric Res 15(1): 9799.

13. Tan SH, Mahmood M \& Ariff A (2013). Synergism effect between inoculum size 
and aggregate size on flavonoid production in centella asiatica (L.) urban (pegaga) cell suspension cultures. Int J Res Eng Tech 2(8): 2321-7308.

14. AL-Taha HAK (2013). Effect of shock and gradual drought by PEG on callus growth and proline accumulation in sour orange (Citrusaurantium). Adv. Agric. Bot. Int J Bio Soc 5(2): 7783.

15. Ahmad MSA, Javed F, Javed S \& Alvi AK (2009). Relationship between callus growth and mineral nutrients uptake in salt-stressed indica rice callus. J Plant Nut 32: 382-394.

16. Mikula A \& Rybczynski J (2001). Somatic embryogenesis of Gentiana genus I. The effect of the preculture treatment and primary explant origin on somatic embryogenesis of Gentiana cruciata L., G. pannonica Scop. and $G$. tibetica ing. Acta. Physiol Plant 23(1): $15-25$.

17. Sharan AK, Dubey SR, Singh BP, Kumar G \& Kumari S (2014). Diversity in callus organization in Eclipta alba Hassak. Int J Adv Res 2(7): 465-473.

18. Hosokawa K, Nakano M, Oikawa Y \& Yamamura S (1996). Adventitious shoot regeneration from leaf, stem and root explants of commercial cultivars of Gentiana. Plant Cell Rep 15: 578581.

19. Abdel-Rahim, EA, Abdel-Fatah OM, EIShemy HAI \& Abd EISamei MB (1998) Growth of date palm callus as affected by amino acids as organic nitrogen source. First International Conference on Date Palms AlAin, UAE 8-10: 19980.

20. Huang B, Han L, Li S \& Yan (2015). Optimization of induction, subculture conditions, and growth kinetics of Angelica sinensis (Oliv.) Diels callus. Pharmacogn Mag 11(43): 574-578.

21. Rao AQ, Hussnain S, Sarfraz, Shahzad M, Sadqib, Bokhari S. Hussain YA, Tayyab \& Rizuddin S (2006). Somatic embrogenesis in wild relatives of cotton (Gossipium spp.). J Zhejiang Uni Sci 291-298.

22. Purohit, $\mathrm{P}$, Bais RT, Singh $\mathrm{P} \&$ khan $\mathrm{S}$ (2015). Comparative Assessment of Lupeol in Wild plant and In Vitro Callus Culture of Hemidesmus indicusby HPLC Technique. UK J Pharmaceut Biosci 3(1): 42-46.

23. Monacelli B, Pasqua G, Cuteri A, Varusio A, Botta B \& Monache GD (1995). Histological study of callus formation and optimization of cell growth in Taxus Baccata. Cytobios 81: 159-170.

24. Jones G, Naidu BP, Waisel Y, Solomon A \& Paleg LG (2006). Occurrence and stress response of $\mathrm{N}$-methylproline compounds in Tamarix species. Phytochem 67(2): 156-160.

25. Putnik-Delic M, Maksimovic I, Venezia A \& Nagl N (2013). Free proline accumulation in young sugar beet plants and in tissue culture explants under water deficiency as tools for assessment of drought tolerance. Rom Agric Res 30: 141-148.

26. Li, X, Yang Y, Jia L, Chen H \& Wei X (2013). Zinc-induced oxidative damage, antioxidant enzyme response and proline metabolism in roots and leaves of wheat plants. Front Plant Sci 89: 1507.

27. Marler TE \& Lindström AJ (2014). Free sugar profile in cycads. Front Plant Sci 5: 526. 